\title{
Tek eksenli sıcak presleme tekniği ile imal edilen magnezyum matrisli kompozit malzemelerin korozyon davranışlarının incelenmesi
}

\author{
Investigation of corrosion behavior of magnesium matrix composite materials produced via \\ uniaxial hot pressing technique
}

\section{Fevzi KELEN*1,a, Tarık AYDOĞMUŞ, ${ }^{2, b}$, Mehmet GAVGALI ${ }^{3, c}$}

${ }^{1}$ Van Yüzüncü Yll Üniversitesi, Van Meslek Yüksekokulu, Motorlu Araçlar ve Ulaştırma Teknolojileri Bölümü, 65080, Van

${ }^{2}$ Van Yüzüncü Yll Üniversitesi, Mühendislik Fakültesi, Makine Mühendisliği Bölümü, 65080, Van

${ }^{3}$ Necmettin Erbakan Üniversitesi, Mühendislik Fakültesi, Makine Mühendisliği Bölümü, 42090, Konya

• Geliş tarihi / Received: 10.03.2021 • • Düzeltilerek geliş tarihi / Received in revised form: 07.10.2021 • Kabul tarihi / Accepted: 18.10 .2021

\section{Öz}

Mevcut çalışmada, tek eksenli sıcak presleme tekniği ile üretilen \%5-\%25 hacimsel oranlarda TiNi içeren magnezyum matrisli kompozit malzemelerin korozyon deneyleri potansiyodinamik polarizasyon (PDS) testleri ile \%3.5 NaCl çözeltisi içerisinde gerçekleştirilmiştir. Kompozit numunelerin korozyon potansiyeli ( $\mathrm{E}_{\text {cor }}$ ) ve korozyon akım yoğunluğu (ícorr) değerleri Tafel ekstrapolasyonu metodu ile belirlenmiştir. Metalografik incelemeler mikroyapıda gözlemlenen değişimlerin elektrokimyasal değerler ile tutarlı olduğunu göstermiştir. Potansiyodinamik polarizasyon analizlerinde güçlendirici içeriğine bağlı olarak korozyon potansiyeli değerlerinin yanı sıra korozyon akım yoğunluğu değerlerininde önemli oranlarda arttığı saptanmıştır. Korozyon sonrası morfolojik incelemelerde numune yüzeylerinde çukurcuk korozyonu ile birlikte kurtçuk korozyonu da gözlenmiştir.

Anahtar kelimeler: Hafif alaşım ve kompozitler, Korozyon, Magnezyum ve alaşımları, Otomotiv malzemeleri, Sıcak presleme, $\mathrm{TiNi}$

\begin{abstract}
In the present study, corrosion tests of magnesium matrix composite materials containing 5-25\% by volume TiNi produced by uniaxial hot pressing technique were carried out with potentiodynamic polarization (PDS) tests in $3.5 \% \mathrm{NaCl}$ solution. Corrosion potential $\left(E_{c o r}\right)$ and corrosion current density $\left(i_{c o r r}\right)$ values of composite specimens were specified by the use of the Tafel extrapolation method. Metallographic examinations have shown that the observed changes in microstructure are consistent with electrochemical values. In potentiodynamic polarization analysis, corrosion potential values alongside corrosion current density values, depending on the reinforcement content, were significantly found to increase. In post-corrosion morphological investigations, filiform corrosion was observed besides pitting corrosion on the sample surfaces.
\end{abstract}

Keywords: Lightweight alloys and composites, Corrosion, Magnesium and its alloys, Automotive materials, Hot pressing, TiNi

\footnotetext{
${ }^{* a}$ Fevzi KELEN; fkelen@yyu.edu.tr; Tel: (0432) 22517 01; orcid.org/ 0000-0003-3900-4503

${ }^{\mathrm{b}}$ orcid.org/ 0000-00020928-5095 $\quad{ }^{\mathrm{c}}$ orcid.org/ 0000-0002-1581-2605
} 


\section{Giriş \\ 1. Introduction}

Düşük yoğunluk, yüksek özgül mukavemet, kolay geri kazanım, mükemmel sönümleme kapasitesi ve iyi dökülebilirlik gibi üstün özelliklerinden dolayı magnezyum ve alaşımları iletişim, spor, tıp ve ulaşım gibi pek çok farklı alanda kullanılmaktadır. Bilhassa düşük ağırlığın kritik bir parametre olduğu havacılık ve otomotiv gibi ulaşım sektörleri için önemli bir potansiyel oluşturmaktadır. Nitekim otomotiv endüstrisinde direksiyon sistemi bileşenleri, debriyaj muhafazası, radyatör, sunroof çerçevesi, pedallar, tekerlek jantları vb. birçok uygulaması bulunmaktadır (Gaines et al., 1996; Fink, 2003; Dobrzański et al., 2008; Luo, 2013; Kelen, 2014; 2018). Fakat bu malzemelerin başlıca tüketimlerinin otomobil ağırlı̆̆ının önemli bir kısmını meydana getiren silindir bloğu, silindir kapağı, transmisyon ve diferansiyel kutusu gibi güç aktarma organları aksamlarının olacağı öngörülmektedir. Zira bu komponentlerdeki kullanımları araç ağırlığında önemli bir hafifleme sağlayarak hem yakıt sarfiyatı hem de yanma sonu açığa çıkan egzoz emisyonlarını minimize edilebilir. Taşıt ağırlığında \%10'luk hafifleme yakıt verimliliğinde \%8'lik iyileşme, toplam ağırlıkta 1 kg'l1k hafifleme ise karbondioksit üretiminde 20 kg'lık düşüş meydana getirmektedir. Ayrıca araç ağırlığındaki düşüş, yakıt etkinliği ve düşük emisyon oluşumunun yanı sıra ivmelenme, frenleme ve manevra kabiliyetlerinide geliştirmektedir. Dolayısıyla magnezyum ve alaşımlarının sadece güç aktarma organları parçaları değil aynı zamanda iç donanım, araç ön alanı, şasi ve karoseri gibi diğer temel sistem ve bileşenlerdeki uygulama sayılarının artırılmasıda büyük önem arz etmektedir. Ne yazık ki zayıf korozyon dirençleri gerek bu alanlardaki kullanımlarını kısıtlamakta gerekse de endüstride demir ve alüminyuma göre daha az tercih edilmelerine neden olmaktadır. Bu bağlamda iyi korozyon dayanımına sahip magnezyum esaslı malzemelerin geliştirilmesi otomotiv endüstrisinin başlica beklentisi olmuştur. Zira otomobillerde geleneksel malzemelerin yerine magnezyum ve alaşımlarının kullanılması ile yakıt ekonomisini iyileştirmenin yanı sıra insan sağlığı ve çevre kalitesi açısından son derece tehlike unsurları ihtiva eden egzoz emisyonlarının asgari düzeye indirgenmeside amaçlanmıştir. Magnezyumun düşük korozyon mukavemeti oksijensiz ortamlarda dahi korozyon oluşumuna yol açan yüksek elektronegatif potansiyeli ve metal yüzeyinde teşekkül eden oksit ya da hidroksit tabakanın birçok sulu veya nemli ortamda kararlı bir yapı sergilememesinden kaynaklanmaktadır (Eliezer et al., 1998; Friedrich and Schumann, 2001; Mordike \& Ebert, 2001; Song \& StJohn, 2005; Ghassemieh, 2011; Joost \& Krajewski, 2017; Esmaily et al., 2017; Kelen, 2021). Magnezyum ve alaşımlarının yapısal ve fonksiyonel özellikleri şekil bellek etkisi, süperelastisite, mükemmel süneklilik, yüksek mukavemet ve tokluk, iyi yorulma dayanımı ve yüksek korozyon direnci gibi üstün özelliklere sahip TiNi intermetalik bileşikler ile iyileştirilmeye çalışılmış olmasına karşın bunların korozyon davranışı üzerindeki etkisine pek değinilmemiştir (Hodgson et al., 1990; Mizuuchi et al., 2004; Otsuka \& Ren, 2005; Esen, 2012; Aydogmus, 2015; Kelen vd., 2018). Özellikle magnezyum matrisli kompozitlerin zayıf korozyon dayanımını geliştirmede yapılan çalışmalar son derece k1sitlidir (Kelen vd., 2019). Mevcut çalışmada, TiNi şekil bellekli alaşımlar ile hacimsel olarak farklı oranlarda takviye edilen magnezyum matrisli kompozit malzemelerin korozyon davranışlarının incelenmesi amaçlanmıştır.

\section{Materyal ve metot}

2. Material and method

Tek eksenli sicak presleme tekniği ile imal edilen magnezyum matrisli kompozit malzemeler TiNi şekil bellekli alaşımlar ile $\% 5, \% 10, \% 15, \% 20$ ve $\% 25$ hacimsel oranlarda takviye edilmiştir. Matris tozlar, Magnezyum ve Metal Tozları End.ve Tic. A. Ş. (Türkiye), takviye tozlar ise AP\&CAdvanced Powders and Coatings Inc. (Kanada), temin edilmiştir. Tablo 1'de kimyasal bileşimleri, geometrik yapıları ve imalat yöntemleri verilen tozlardan magnezyumun saflığı üretici firma tarafından minimum \%99 olarak belirtilirken alaşım tozların ise imalatçı şirket aracılığıyla sağlanan sertifikalı kimyasal analizler sonucu saptanmıştır. Magnezyum ve TiNi mikro partikül tozlar yukarıda ifade edilen miktarlarda seramik bir kap içerinde $10 \mathrm{dk}$ boyunca karıştırılmış, akabinde Ø80/40X50 mm ebatlarındaki silindirik grafit kalıplarda, $600^{\circ} \mathrm{C}$ sicaklıkta, $50 \mathrm{MPa}$ basınçta 1 saat süre ile inert gaz atmosferinde sinterlenmiştir. Elektrokimyasal analizlerde kullanılmak üzere kompozit malzemelerden tel erozyon vasitasiyla $5 \times 5 \times 10 \mathrm{~mm}^{3}$ boyutlarinda numuneler elde edilmiştir. Metalografik hazırlama işlemlerinden sonra numuneler etil alkol içerisinde $5 \mathrm{dk}$ ultrasonik temizlemeye tabi tutulmuştur. \%3.5 $\mathrm{NaCl}$ çözeltisinde (Baboian, 2005), PCI14/750 potansiyostat/galvanostat test cihazı kullanılarak gerçekleştirilen korozyon deneylerinde referans elektrot (RE) olarak doygun gümüş/gümüş klorür $(\mathrm{Ag} / \mathrm{AgCl})$, karşı1t elektrot $(\mathrm{CE})$ olarak platin $(\mathrm{Pt})$ ve çalışma elektrodu (WE) olarak da yüzey alanı 
$0,25 \mathrm{~cm}^{2}$ olan numuneler kullanılmıştır. Potansiyodinamik polarizasyon (PDS) analizleri öncesi, elektrotlar açık devre potansiyellerinde kararlılığa ulaşana kadar bekletilmiş sonrasında eğriler, $-2 \mathrm{~V}$ ile $1 \mathrm{~V}$ arasında katodikten anodik yöne doğru $0.5 \mathrm{mV} / \mathrm{sn}$ tarama hızında elde edilmiştir. Elektrokimyasal impedans spektroskopi (EIS) analizleri ise $100000 \mathrm{~Hz}$ 'den $0.01 \mathrm{~Hz}$ 'e kadar olan frekans aralıklarında tarama yapılarak oluşturulmuştur.

Tablo 1. Kompozit numunelerin üretiminde kullanılan matris ve takviye tozların özellikleri

Table 1. Properties of matrix and reinforcement powders used in the production of composite samples

\begin{tabular}{|c|c|c|c|c|c|c|c|}
\hline \multirow{2}{*}{$\begin{array}{c}\text { Matris ve Takviye } \\
\text { Tozlar }\end{array}$} & \multicolumn{4}{|c|}{ Kimyasal Bileşim (\%) } & \multirow{2}{*}{$\begin{array}{c}\text { Toz Boyutu } \\
(\mu \mathrm{m})\end{array}$} & \multirow{2}{*}{$\begin{array}{c}\text { Geometrik } \\
\text { Şekil }\end{array}$} & \multirow{2}{*}{$\begin{array}{l}\text { İmalat } \\
\text { Yöntemi }\end{array}$} \\
\hline & $\mathrm{Mg}$ & $\mathrm{Ti}$ & $\mathrm{Ni}$ & Diğer & & & \\
\hline $\mathrm{Mg}^{*}$ & 99 & & & Kalan & $100-300$ & $\begin{array}{l}\text { Yuvarlak } \\
\text { ve } \\
\text { Düzensiz }\end{array}$ & Mekanik \\
\hline $\mathrm{TiNi}^{* *}$ & & 49.2 & 50.8 & & $0-45$ & Küresel & Atomizasyon \\
\hline
\end{tabular}

*; \% Ağırlık, **; \% Atomik

\section{Bulgular ve tartışma}

\section{Results and discussion}

Magnezyum matrisli kompozit malzemelerin açık devre potansiyel (OCP) değişimleri ve potansiyodinamik polarizasyon (PDS) eğrileri sırasıyla Şekil 1a ve b'de verilmiştir. Bu analizlerden elde edilen önemli bazı korozyon parametreleri ise Tablo 2'de sunulmuştur. Kompozit malzemelerin açık devre potansiyel değişimlerinde artan takviye oranı ile birlikte potansiyelin daha soy değerler aldığı gözlenmiştir. $\mathrm{Bu}$ soylaşma davranışı numune yüzeylerinde teşekkül eden kalın oksit tabakasından kaynaklanmaktadır. Potansiyodinamik polarizasyon eğrilerinde ise artan takviye miktarı ile beraber hem korozyon potansiyeli $\left(\mathrm{E}_{\mathrm{cor}}\right)$, hem de korozyon akım yoğunluğu ( $\left.i_{\text {corr }}\right)$ değerlerinin arttığ 1 saptanmıştır. Standart elektrot potansiyeli $-2.37 \mathrm{~V}$ civarında olan magnezyumun sodyum klorür çözeltisi içerisindeki korozyon potansiyeli değişmektedir. Deneysel çalışmalarda elektrolitte çözünmüş \% $\mathrm{NaCl}$ miktarına bağlı olarak bu değerin $\quad-1.5$ ile $\quad-1.7 \quad \mathrm{~V}$ civarında olduğu belirtilmiştir (Song \& Atrens, 1999). Mevcut çalışmada tüm numunelerin korozyon potansiyellerinin -1.3 ile $-1.5 \mathrm{~V}$ arasında değiştiği tespit edilmiştir. Potansiyel değerlerinde gözlemlenen bu değişim, kompozitlerin matris yapısına, içerdiği takviye miktarına ve sinterleme sıcaklığına atfedilmiştir. Üretilen malzemelerin potansiyodinamik polarizasyon eğrilerinde çukurcuk potansiyelinin $\left(\mathrm{E}_{\mathrm{pit}}\right)$, net bir biçimde gözlenmemesi bu değerlerin korozyon potansiyeli $\left(E_{\text {cor }}\right)$ değerlerine çok yakın olmasından kaynaklanmaktadır. Zira solüsyondaki çözünmüş oksijenin indirgenme tepkimesi korozyon reaksiyonunu bastırmakta bu durum çukurcuk potansiyelinin gözlenmemesine sebep olmaktadır. Deneysel çalışmalarda numuneler yoğun çözeltiye daldırıldıktan hemen sonra çukurcukların oluşmaya başladığı ve karşıt elektrotta $\mathrm{H}_{2}$ gaz çıkışı gözlenmiş̧ir. Ancak katodik bölgede akım yoğunluğunun ve numune yüzeyinde korozyon ürünü oluşumunun yüksek olması çözünme mekanizmasının genel korozyon şeklinde ilerlediğini göstermektedir. Magnezyum yüzeyinde teşekkül eden oksit film tabakası suda çözünebilir olması ve hekzagonal kristal yapı ile arasındaki geometrik uyumsuzluktan dolayı birçok kez koruyucu özellik sergilememektedir. Bu durum takviye tozların bulunduğu bölgelerde oksit film yapisında süreksizlikler meydana getirerek pasif tabakada kırılma ve ayrılmalara yol açan bası gerilmelerine neden olabilir. Ayrıca ortamdaki klor iyonları pasif tabakaya nüfus ederek asidik yapıdaki magnezyum tuzlarını oluşturup, numunelerin hasara uğramasını hızlandırabilir (Ferrando, 1989; Hillis, 2006). Nitekim Şekil 2'de verilen makro ölçekteki yüzey görüntüleri bu açıklamaları doğrular niteliktedir. Literatürde sulu çözeltilerde magnezyum yüzeyinde teşekkül eden pasif film morfolojisinin $\mathrm{MgO}$ ve $\mathrm{Mg}(\mathrm{OH})_{2}$ 'den meydana gelen tabakalı bir yapı olduğu ifade edilmektedir. Genel olarak $\mathrm{MgO}, \mathrm{Mg}(\mathrm{OH})_{2}$ 'den daha kararlı bir yapıya sahiptir (Song \& Atrens, 1999). Kompozit malzemelerde artan takviye oranı ile birlikte korozyon hızının da artması numune içeriğinde azalan matris oranından kaynaklandığı düşünülmektedir. Zira bununla birlikte pasif tabakada oluşan $\mathrm{MgO}$ miktarı da azalmaktadır. Mevcut çalışmada artan takviye oranı ile birlikte her ne kadar korozyon hızının arttığı saptansada bu artışın çalışılan tüm oranlarda tam yoğunluğa ulaşılmış olması nedeni ile sınırlı olduğu gözlenmiştir. Bir önceki çalışmada (Kelen vd., 
2019) düşük sinterleme sicaklı̆g $1\left(420^{\circ} \mathrm{C}\right)$ sonucu mikroyapıda meydana gelen gözeneklerin koruyucu pasif tabakayı zayıflatarak numunelerde korozyon direncinin önemli oranda düşmesine yol açtığ 1 belirlenmiştir. Elektrolitteki klor iyonu konsratrasyonu bu gözenekli yapılarda artarak oksit tabakanın hasara uğramasına ve korozyon dayanımının düşmesine neden olmaktadır (Kelen vd., 2019). Tam yoğunluğa ulaşılmamış kompozitlerde $\% 5$ ile $\% 25$ takviye içeren numunelerde korozyon potansiyeli $-1.550 \mathrm{~V}$ ile $1.410 \mathrm{~V}$ arasında değişir iken bu değerler gözenek içermeyen kompozitlerde $-1.525 \mathrm{~V}$ ile $-1.329 \mathrm{~V}$ arasindadır (Tablo 2). Dolayısiyla sinterleme sıcaklığının mevcut çalışmada bir öncekine nazaran $420^{\circ} \mathrm{C}$ sıcaklıktan $600^{\circ} \mathrm{C}$ 'ye çıkarılması, kompozit malzemelerin korozyon hızının önemli oranda düşmesini ve korozyon direncinin iyileşmesini sağlamıştır. Yapılan morfolojik analizlerde tüm numunelerde çukurcuk korozyonu izine rastlanılmıştır (Şekil 3a). Ayrıca kompozitlerde kurtçuk (filiform) korozyonu da saptanmıştır. Kurtçukların dar ve yarı silindirik iplikcikler şeklinde çukurdan dışarı doğru uzandığı tespit edilmiştir (Şekil 3c). Deneysel çalışmalarda magnezyum esaslı malzemelerin klorlu çözeltilere maruz kalmaları halinde çukurcuk korozyonu

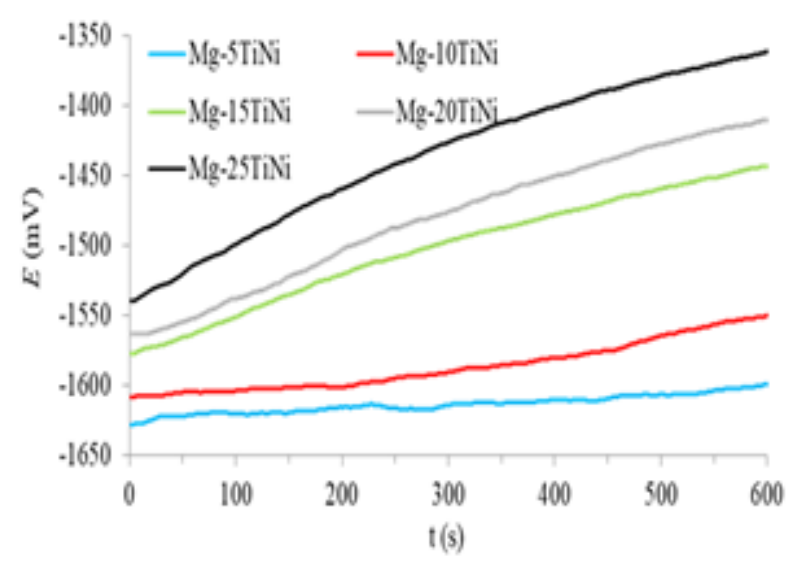

(a) biçiminde hasara uğradıkları belirtilmektedir (Ghali et al., 2004; Lindström et al., 2004; Kelen vd., 2019). Kompozit malzemelerde korozyonun genel olarak matris takviye ara yüzeyinde ilerlediği ve takviye materyalinin korozyona uğramadığ 1 gözlenmiştir. Magnezyuma göre daha soy karakterdeki takviye elemanlarının korozyona uğramamas1 yüzeyinde oluşan ince $\mathrm{TiO}_{2}$ tabakasından kaynaklanmaktadır. Matris fazın yoğun olarak hasara uğraması sonucu takviye tozların yapı içerisinden koparak ayrıldığı tespit edilmiştir (Şekil 3d). Ayrıca artan güçlendirici oranlarında takviye fazının tercihli olarak belli bölgelerde topaklandığı saptanmıştır. Bu durum lokal katot oranını artırmakta ve küçük anot/büyük katot olarak adlandırılan korozyon türüne yol açmaktadır. Çukurcukların iç bölgelere doğru hızla ilerlemesine neden olan bu mekanizma takviye elemanlarının yapı içerisinden ayrılma sürecini hızlandırmaktadır. Önceki çalışmada, düşük sinterleme sıcaklığı neticesinde oluşan poroziteler gerek takviye tozların matris fazdan ayrılma sürecinin daha etkin olmasına gerekse de yüzeyde süreksizliklere neden olarak pasif tabakada yarılmalara yol açtığı gözlenmiştir (Kelen vd., 2019).

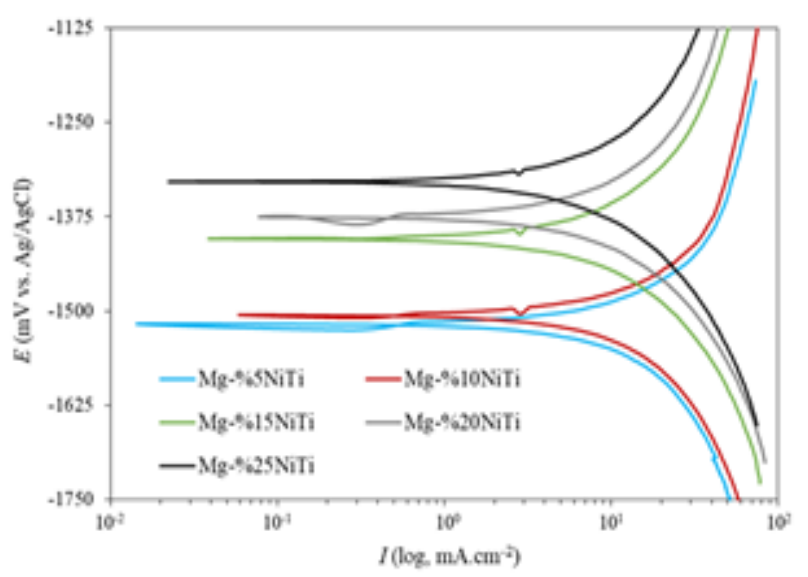

(b)

Şekil 1. Kompozit malzemelerin açık devre potansiyel (OCP) ve potansiyodinamik polarizasyon (PDS) eğrileri (a) OCP, (b) PDS

Figure 1. Open circuit potential (OCP) and potentiodynamic polarization (PDS) curves of composite materials (a) $O C P$, (b) PDS 
Tablo 2. Kompozit malzemelerin polarizasyon analizlerinden elde edilen önemli bazı korozyon parametreleri Table 2. Corrosion parameters obtained from polarization analyzes of composite materials

\begin{tabular}{|c|c|c|c|c|c|c|c|}
\hline $\begin{array}{l}\text { Matris } \\
\text { Faz }\end{array}$ & $\begin{array}{l}\text { Takviye } \\
\text { oranı } \\
(\%) \\
\end{array}$ & $\begin{array}{l}E_{\text {ocp }} \\
(\mathbf{m V})\end{array}$ & $\begin{array}{l}E_{\text {corr }} \\
(\mathbf{m V})\end{array}$ & $\begin{array}{l}I_{\text {corr }} \\
\left(\mathbf{m A} / \mathrm{cm}^{2}\right)\end{array}$ & $\begin{array}{l}\text { Beta } A \\
(\mathrm{mV} / \text { dec. })\end{array}$ & $\begin{array}{l}\text { Beta } \\
(\mathrm{mV} / \text { dec. })\end{array}$ & $\begin{array}{l}\text { Korozyon } \\
\text { Hizi (mpy) } \\
\mathbf{x 1 0}^{3}\end{array}$ \\
\hline \multirow{5}{*}{ 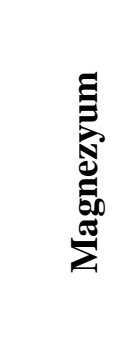 } & 5 & -1550 & -1525 & 12.60 & 212 & 287 & 12.60 \\
\hline & 10 & -1548 & -1509 & 15.10 & 329 & 299 & 15.10 \\
\hline & 15 & -1429 & -1404 & 17.15 & 401 & 477 & 16.84 \\
\hline & 20 & -1385 & -1403 & 20.20 & 691 & 484 & 20.20 \\
\hline & 25 & -1353 & -1329 & 24.10 & 983 & 518 & 23.84 \\
\hline
\end{tabular}

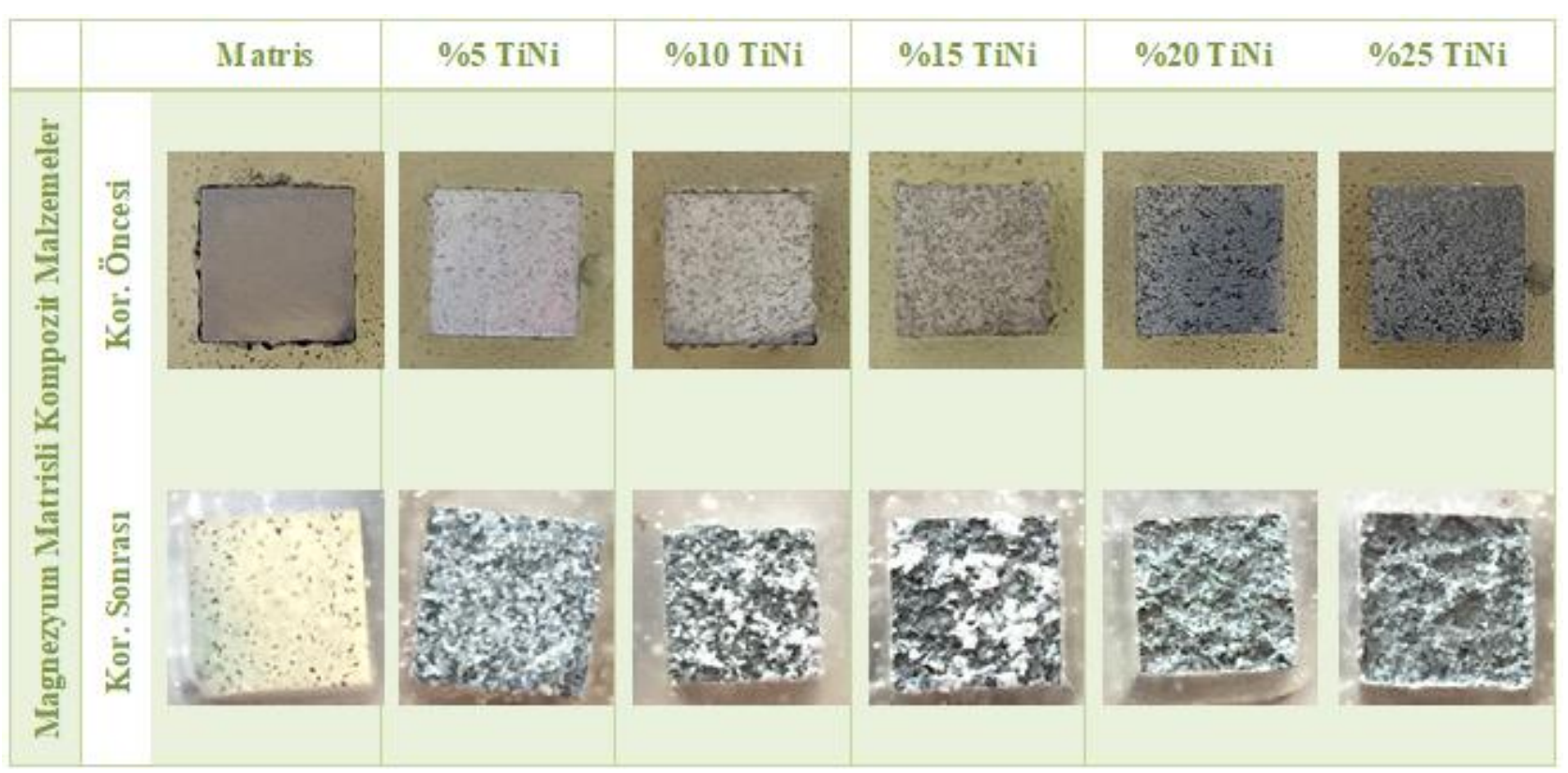

Şekil 2. Magnezyum matrisli kompozit malzemelerin korozyon öncesi ve sonrası makroskobik görüntüleri Figure 2. Macroscopic images of magnesium matrix composite materials before and after corrosion

Şekil 4'te kompozit malzemelerin elektrokimyasal impedans spektroskopi (EIS) analizleri sonrasi elde edilen Nyquist eğrileri verilmiştir. Bu grafiklerden yüksek frekanstan ortak frekans bölgesine bir kapasitif yarı dairenin teşekkülü ve düşük frekans bölgesinde bir indüktif döngünün varlığı görülmektedir. Numunelerde artan güçlendirici miktarı ile birlikte meydana gelen bu dairenin yarıçapı önemli mertebede azalmaktadır. $\mathrm{Bu}$ kapasitif davranış yüzeyde oluşan oksit film direncinin düşmesinden kaynaklanmaktadır. Pasif film direncinin azalması oksit tabakanın oldukça kalın, gözenekli, gevrek ve dayanıksız olduğuna işaret etmektedir. Üretilen kompozit malzemelerin motor bloğu, silindir kapağı, transmisyon kutusu ve diferansiyel kutusu gibi güç aktarma organları bileşenleri imalatında kullanılmak üzere geliştirilmesi ve bunların servis şartlarında klorlu çözeltilere maruz kalmalarından dolayı testler yoğun \%3.5 NaCl çözeltisi içerisinde gerçekleştirilmiştir (Baboian, 2005). Diğer bir ifade ile deneysel çalışmalarda ASTM tarafından otomotiv endüstrisi için belirlenen test çözeltileri standartları, dikkate alınarak yüksek dirençli çözelti tercih edilmiştir. Analizlerin ilk aşamasında meydana gelen çok yüksek reel empedanstan da anlaşılan bu yüksek direnç numune/çözelti ara yüzeyinde faradik proseslerin, difüzyonun deney sırasında da sürdüğünü göstermektedir. Kapasitif dirençteki düşüş numunelerin zayıf korozyon mukavemetinden kaynaklandığı düşünülmektedir. Düşük frekanslarda gözlemlenen indüktif döngü ise ağırlık kaybı sonucu meydana gelmekte ve zamanla yüzeye $\mathrm{Cl}^{-}$iyonu emiliminin arttığını göstermektedir. 


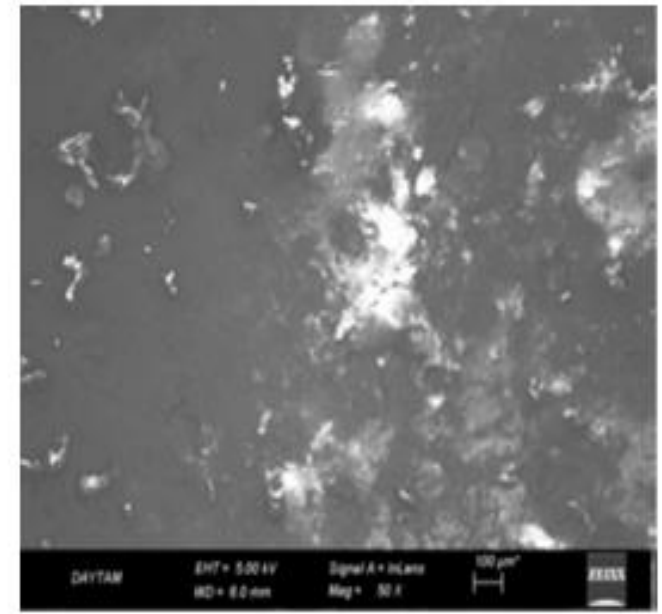

(a)

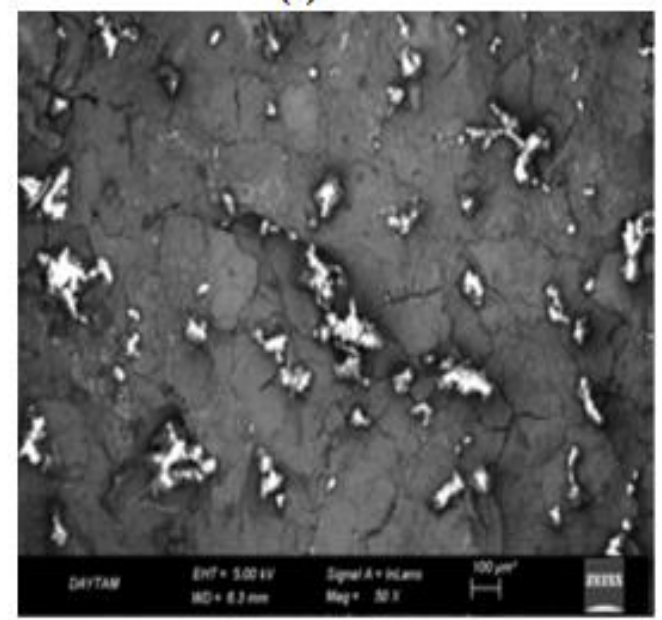

(c)

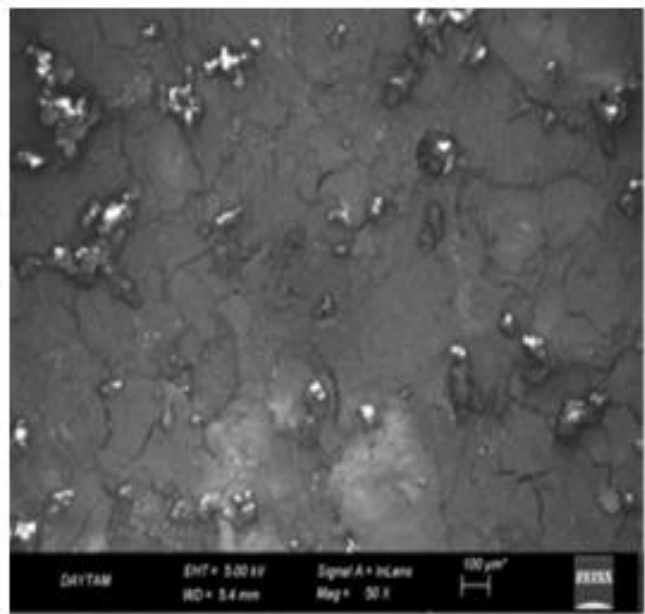

(b)

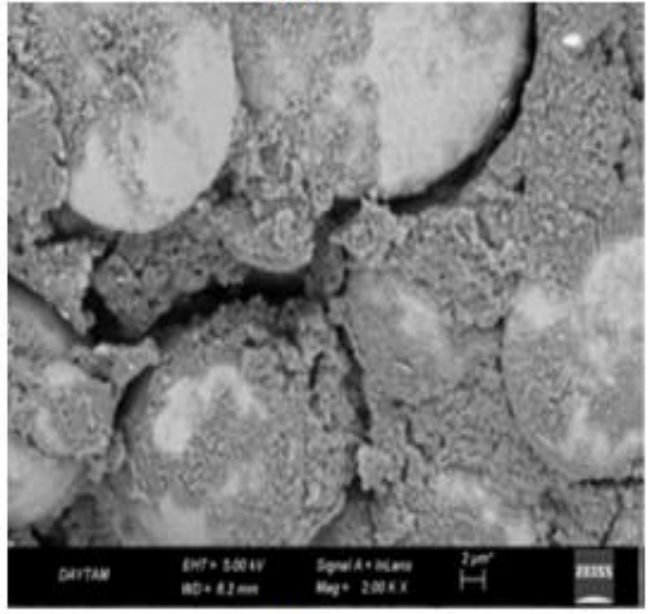

(d)

Şekil 3. Kompozit malzemelerin SEM görüntüleri a) \%5TiNi, b) \%15TiNi ve c-d) \% 25TiNi

Figure 3. SEM images of composite materials a) $5 \% \mathrm{TiNi}$, b) $15 \% \mathrm{TiNi}$ and c-d) $25 \% \mathrm{TiNi}$

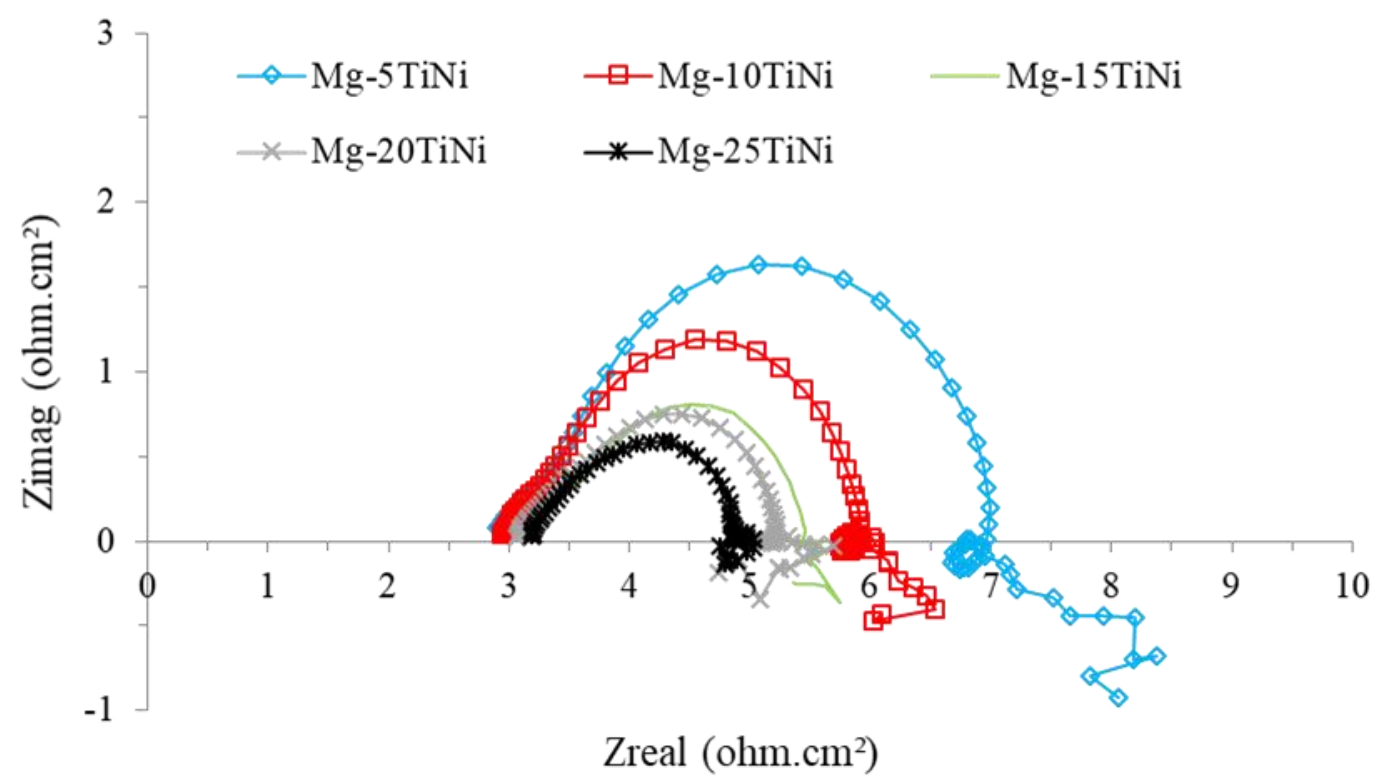

Şekil 4. Kompozit malzemelerin elektrokimyasal empedans spektroskopi (EIS) eğrileri Figure 4. Electrochemical impedance spectroscopy (EIS) curves of composite materials 


\section{Sonuçlar \\ 4. Conclusions}

Otomobil güç aktarma organları bileşenleri imalatında kullanılmak üzere geliştiren kompozit malzemelerin gerçekleştirilen korozyon deneylerinde numunelerin açik devre potansiyel değişimlerinin zamanla artığı tespit edilmiştir. Potansiyodinamik polarizasyon analizlerinde ise artan takviye miktarı ile birlikte kompozit malzemelerin korozyon potansiyeli $\left(\mathrm{E}_{\mathrm{cor}}\right)$, değerlerinin yanı sıra korozyon akım yoğunluğu (i $\left.i_{\text {corr }}\right)$ değerlerinin de arttığ 1 saptanmıştır. Morfolojik analizlerde kompozit malzemelerde çukurcuk korozyonu gözlenmiştir. Ayrıca kurtçuk korozyonu türüne de rastlanılmıştır. Kurtçukların dar ve yarı silindirik iplikcikler şeklinde çukurdan dışarı doğru uzandığ 1 saptanmıştır. Matris fazın yüksek elektronegatif potansiyeli ve yüksek agresif çözelti oksit tabakada hasarlar oluşturarak numuneleri çukurcuk korozyonuna karşı duyarlı hale getirdiği belirlenmiştir. Kompozit malzemelerde matris-takviye arasında sınır teşkil eden ara yüzeylerin ve soy karakterdeki TiNi takviye fazının çukurcuk (pitting) morfolojisi üzerinde önemli etkiye sahip olduğu gözlenmiştir. Kompozit numunelerin potansiyel değerlerinin matris yapıs1, takviye miktarı ve sinterleme sıcaklığına bağlı olarak değiştiği tespit edilmiştir.

\section{Teşekkür}

\section{Acknowledgement}

$\mathrm{Bu}$ çalışmayı finansal olarak destekleyen Türkiye Bilimsel ve Teknolojik Araştırma Kurumu'na (Proje No: 215M808) ve Van Yüzüncü Y1l Üniversitesi Bilimsel Araştırma Projeleri Birimi Başkanlığı'na (Proje No: 2015-FBE-D275), teşekkürlerimizi sunarız. Ayrıca saf magnezyum tozların temin edildiği, Magnezyum ve Metal Tozları Endüstri ve Ticaret Anonim Şirketine teşekkür ederiz.

\section{Yazar katkısı}

Author contribution

Yazarların çalışmadaki katkı oranları eşittir.

\section{Etik beyanı}

Declaration of ethical code

$\mathrm{Bu}$ makalenin yazarları, mevcut çalışmada kullanılan materyal ve yöntemlerin etik kurul izni ve/veya yasal-özel izin gerektirmediğini beyan etmektedir.

\section{Çıkar çatışması beyanı \\ Conflicts of interest}

Mevcut çalışma kapsamında herhangi bir kurum veya kişi ile çıkar çatışması bulunmamaktadır.

\section{Kaynaklar \\ References}

Aydogmus, T. (2015). Processing of interpenetrating $\mathrm{Mg}-\mathrm{TiNi}$ composites by spark plasma sintering. Materials Science and Engineering: A, 624, 261270. https://doi.org/10.1016/j.msea.2014.11.092

Baboian, R. (2005). Automotive, Baboian R. (Ed.), Corrosion Tests and Standards: Application and Interpretation-Second Edition (pp. 673-687.). West Conshohocken; U.S.A: ASTM. https://www.astm.org/DIGITAL_LIBRARY /MNL /PAGES/MNL11004M.htm

Dobrzański, L. A. Tański, T, Čížek, L., \& Domagała, J. (2008). Mechanical properties and wear resistance of magnesium casting alloys. Journal of Achievements in Materials and Manufacturing Engineering, 31(1), 83-90.

Eliezer, D. Aghion, E., \& Froes, F. S. (1998). Magnesium science, technology and applications. Advanced Performance Materials, 5(3), 201-212.

Esen, Z. (2012). The effect of processing routes on the structure and properties of magnesium-TiNi composites. Materials Science and Engineering: A, 558, 632-640.

Esmaily, M., Svensson, J. E., Fajardo, S., Birbilis, N., Frankel, G. S., Virtanen, S., Arrabal, R., Thomas. S., \& Johansson, L. G. (2017). Fundamentals and advances in magnesium alloy corrosion. Progress in Materials Science, 89, 92-193. https://doi.org/10.1016/j.pmatsci.2017.04.011

Ferrando, W. A. (1989). Review of corrosion and corrosion control of magnesium alloys and composites. Journal of Materials Engineering, 11(4), 299-313.

Fink, R. (2003). Die casting magnesium, Kainer, K. U. (Ed.), Magnesium Alloys and Technology (pp. 23-44.). Germany WILEY-VCH Verlag.

Friedrich, H., \& Schumann, S. (2001). Research for a "new age of magnesium" in the automotive industry. Journal of Materials Processing Technology, 117(3), 276-281. https://doi.org/10.1016/S0924-0136(01)00780-4

Gaines, L. Cuenca, R. Wu, S., \& Stodolsky, F. Argonne National Lab., Washington, DC. (1996). Potential automotive uses of Wrought Magnesium Alloys. United States. Erişim adresi 
https://doi.org/10.2172/425305-03-Ocak2021.pdf

Ghali, E. Dietzel, W., \& Kainer, K.U. (2004). General and localized corrosion of magnesium alloys: a critical review. Journal of Materials Engineering And Performance, 13(1), 7-23. https://doi.org/10.1361/10599490417533

Ghassemieh, E. (2011). Materials in automotive application, state of the art and prospects. New trends and Developments in Automotive Industry, 20, 364-394. https://doi.org/10.5772/13286

Hillis, J. (2006). Corrosion. Friedrich, H. E. Mordike, B. L. (Ed.), Magnesium technology (pp. 469-498). Berlin; Germany: Springer-Verlag.

Joost, W.J., \& Krajewski, P. E. (2017). Towards magnesium alloys for high-volume automotive applications. Scripta Materialia, 128, 107-112. https://doi.org/10.1016/j.scriptamat.2016.07.035

Kelen, F. (2014). Motorlu taşı1 emisyonlarının insan sağlığ1 ve çevre üzerine etkileri. Yüzüncü $Y_{l} l$ Üniversitesi Fen Bilimleri Enstitüsü Dergisi, 19(1-2), 80-87.

Kelen, F. (2018). TiNi ile takviye edilmiş $M g / A Z 91$ matrisli kompozitlerin üretimi ve karakterizasyonu [Doktora Tezi, Atatürk Üniversitesi, Fen Bilimleri Enstitüsü].

Kelen, F. Gavgali, M., \& Aydogmus, T. (2018). Microstructure and mechanical properties of a novel TiNi particulate reinforced AZ91 metal matrix composite. Materials Letters, 233, 12-15. https://doi.org/10.1016/j.matlet.2018.08.121

Kelen, F. Aydoğmuş, T. Gavgalı, M., \& Dikici, B. (2019). Toz metalürjisi yöntemi ile üretilmiş magnezyum matrisli kompozitlerin korozyon duyarlılıkları. Bitlis Eren Üniversitesi Fen Bilimleri Dergisi, 8(3), 914-920.

Kelen, F. (2021). Magnezyum ve alaşımlarının otomotiv endüstrisindeki önemi ve uygulamaları. Journal of the Institute of Science and Technology, 11(1), 548-562. https://doi.org/10.21597/jist.789612.

Lindström, R. Johansson, L. G. Thompson, G. E. Skeldon, P., \& Svensson, J. E. (2004). Corrosion of magnesium in humid air. Corrosion Science, 46(5), 1141-1158. https://doi.org/10.1016/j.corsci.2003.09.010

Luo, A. A. (2013). Applications: aerospace, automotive and other structural applications of magnesium. Fundamentals of Magnesium Alloy Metallurgy, 266-316.

Mizuuchi, K. Inoue, K. Hamada, K. Sugioka, M. Itami, M. Fukusumi, M., \& Kawahara, M. (2004). Processing of TiNi SMA fiber reinforced AZ31 $\mathrm{Mg}$ alloy matrix composite by pulsed current hot pressing. Materials Science and Engineering: A, 367(1-2), 343-349.

Mordike, B. L., \& Ebert, T. (2001). Magnesium: properties-applications-potential. Materials Science and Engineering: A, 302(1), 37-45.

Otsuka, K., \& Ren, X. (2005). Physical metallurgy of Ti-Ni-based shape memory alloys. Progress in Materials Science, 50(5), 511-678. https://doi.org/10.1016/j.pmatsci.2004.10.001

Song, G. L., \& Atrens, A. (1999). Corrosion mechanisms of magnesium alloys. Advanced Engineering Materials, 1(1), 11-33.

Song, G., \& StJohn, D.H. (2005). Corrosion of magnesium alloys in commercial engine coolants. Materials and Corrosion, 56(1), 15-23. https://doi.org/10.1002/maco.200403803 